\title{
Multidisciplinary intervention for reducing malnutrition among children in the Islamic Republic of Iran
}

R. Sheikholeslam, ${ }^{1}$ M. Kimiagar, ${ }^{2}$ F. Siasi ${ }^{3}$ Z. Abdollahi, ${ }^{1}$ A. Jazayeri, ${ }^{3}$ K. Keyghobadi, ${ }^{3}$ M. Ghaffarpoor, ${ }^{3}$ F. Noroozi, ${ }^{4}$ N. Kalantari, ${ }^{2}$ M. Minaei, ${ }^{1}$ F. Eslami ${ }^{2}$ and H. Hormozdyari ${ }^{2}$

مُداخلة متعددة البجالات لتقليص سوء التغذية لدى الأطفال بجمهورية إيران الإسلامية

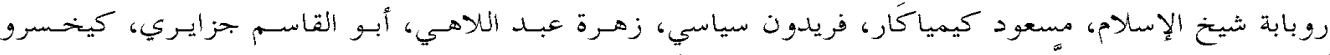

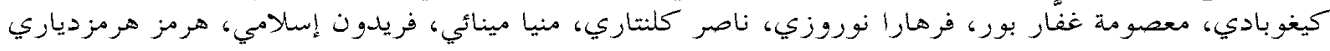

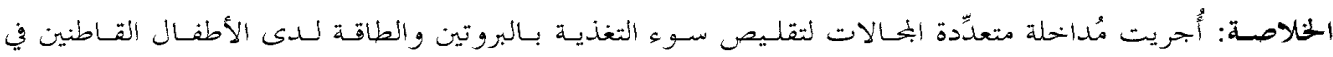

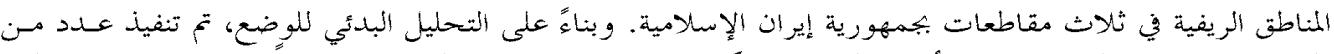

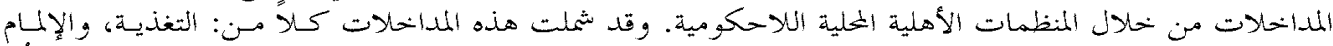

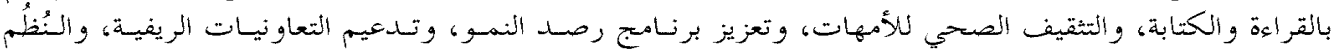

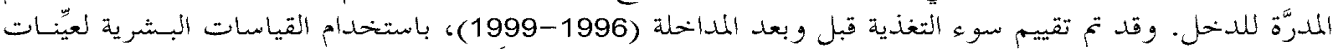

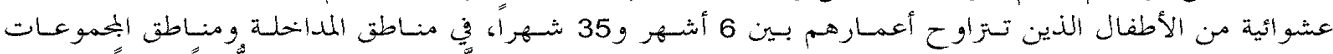

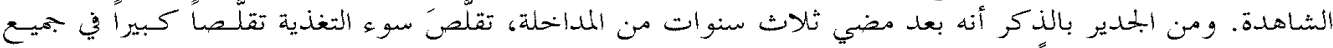

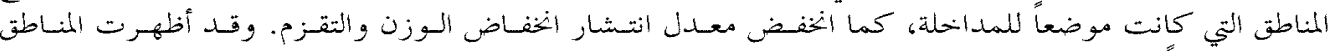

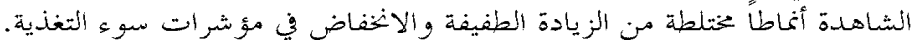

ABSTRACT A multidisciplinary intervention to reduce protein-energy malnutrition among children in rural areas was piloted in 3 provinces of the Islamic Republic of Iran. Based on an initial situation analysis, a range of interventions were implemented through local nongovernmental organizations, including nutrition, health and literacy education for mothers, improved growth monitoring and fostering rural cooperatives and income generation schemes. Malnutrition before and after the intervention (in 1996 and 1999) was assessed using anthropometric measurements of random samples of children aged 6-35 months in control and intervention areas. Three years into the intervention, all indicators of malnutrition had consistently decreased in all intervention areas and the prevalence of underweight and stunting was significantly lower. Control areas showed a mixed pattern of small increases and decreases in malnutrition indicators.

\begin{abstract}
Intervention multidisciplinaire pour réduire la malnutrition chez l'enfant en République islamique d'Iran

RÉSUMÉ Une intervention multidisciplinaire pour réduire la malnutrition protéino-énergétique chez l'enfant en zone rurale a été menée dans trois provinces de la République islamique d'Iran. Sur la base d'une analyse de la situation initiale, diverses interventions, comprenant l'éducation nutritionnelle et sanitaire des mères et leur alphabétisation, le renforcement du programme de surveillance de la croissance, la promotion des coopératives rurales et de projets générateurs de revenus, ont été mises en oeuvre par le biais d'organisations non gouvernementales. La malnutrition avant et après l'intervention (en 1996 et en 1999) a été évaluée en utilisant les mesures anthropométriques réalisées sur des échantillons aléatoires d'enfants âgés de 6 à 35 mois dans les zones témoins et dans les zones d'intervention. Trois ans après le début de l'intervention, tous les indicateurs de la malnutrition avaient diminué systématiquement dans toutes les zones d'intervention et la prévalence du déficit pondéral et du retard de croissance était significativement plus faible. Les zones témoins montraient un tableau diversifié avec de petites augmentations et diminutions des indicateurs de la malnutrition.
\end{abstract}

${ }^{1}$ Department of Nutrition, Ministry of Health and Medical Education, Tehran, Islamic Republic of Iran. ${ }^{2}$ National Nutrition and Food Technology Research Institute, Tehran, Islamic Republic of Iran.

${ }^{3}$ Tehran University School of Public Health, Tehran, Islamic Republic of Iran.

${ }^{4}$ Agriculture Planning and Economic Institute, Tehran, Islamic Republic of Iran. 


\section{Introduction}

Considerable efforts have been made throughout the world to promote the health of communities. Although these efforts have decreased mortality rates, especially among infants, protein-energy malnutrition is still the most important nutritional problem in many developing countries [1], including the Islamic Republic of Iran. The last national survey in the country in November 1998 showed that in rural areas $12.8 \%$ of under 5-year-olds suffered from mild to severe nutritional stunting, $13.7 \%$ of them were underweight and $4.8 \%$ of them suffered from wasting [2]. The prevalence of underweight among children under 6 months is similar to a well-nourished community $(3 \%)$, but the prevalence of underweight increases after this age, peaking at $13.8 \%$ in 2-year-olds (aged 24-35 months). In order to prevent the problem of underweight, therefore, interventions should be focused on children under 2 years old before they display the symptoms of underweight.

Some of the factors known to affect the development of malnutrition include poor nutritional knowledge of mothers, illiteracy, inappropriate child feeding, low household income, food shortages and poor sanitation practices that involve children in a vicious cycle of infection and malnutrition [3].

Experiences of other countries such as Indonesia and India show that multidisciplinary interventions in the community using non-governmental organizations (NGOs) with expertise in food and nutrition development can reduce protein-energy malnutrition [4]. In the present study, a pilot intervention for decreasing malnutrition among children, with the emphasis on intersectoral cooperation and obtaining the participation of the community, especially mothers, was carried out in rural areas of 3 provinces of the Islamic Republic of Iran. The main target of the intervention was to reduce the malnutrition of children aged less than 3 years old to one-third of its initial figure. This paper outlines the stages of the programme: the preliminary data gathering to plan the intervention, the implementation of the intervention and the collection and analysis of pre- and postintervention anthropometric measurements of children.

\section{Methods}

\section{Intervention areas}

This study was performed from 1996 to 1999 in rural areas of 3 different districts of 3 provinces: Ilam (Ilam province), Bardsir (Kerman province) and Borazjan (Bushehr province). These areas were selected on the basis of a number of criteria: the high prevalence of malnutrition among children under 5 years old based on routine data from the primary health care system; a good primary care infrastructure, efficient management and sufficient health personnel; and the appropriate capacity of relevant sectors in the area, including agriculture and education. In each district of each province, all the villages were covered by the intervention: 139 in Ilam, 122 in Borazjan and 176 in Bardsir.

To select control areas for comparison with the intervention areas, another district was selected from each province with a similar socioeconomic situation and a similar prevalence of malnutrition, and data was collected from all the villages in the district.

\section{Sample}

To demonstrate a reduction in malnutrition of children aged less than 3 years old to one-third of its initial figure, the required sample size was estimated to be about 700

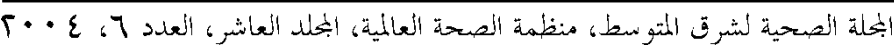


children in each area $(\alpha=0.05, \beta=0.01)$. Considering the ratio of children aged less than 3 years to the total population, about 2000 households were needed to obtain the required number of children. With the success of the national family planning programme in recent years, it was possible to reduce the number of children in the samples. In this way, 659 children aged 6-35 months from Ilam, 532 children from Borazjan, and 512 children from Bardsir were selected by systematic random sampling (Table 1).

\section{Situation analysis}

In the first phase, a situation analysis was made of the incidence of malnutrition and factors affecting the problem among children of the study areas. The situation analysis aimed to collect and analyse basic socioeconomic and health information from households and agricultural information about the areas using questionnaires. Data were collected about: knowledge, attitudes and practices of mothers about child feeding, growth monitoring, family plan- ning, sanitation, safe drinking water, food production and socioeconomic conditions. Food consumption patterns of the household and child were studied with a food frequency questionnaire, and by weighing samples of consumed foods.

\section{Anthropometric measures}

The first phase included taking baseline anthropometric measures of children in the intervention and control areas to determine the prevalence of malnutrition. The weight of the children was measured using pan weight scales and height using a height meter. The precision of the scales was checked with control weights. The percentage prevalence of underweight (weight-for-age), nutritional stunting (height-for-age) and wasting (weight-forheight) in the control and intervention areas were calculated. The reference for anthropometric measures was the World Health Organization/National Center for Health Statistics (WHO/NCHS) standards [5] and the cut-offs were -2 standard deviations from the mean.

\begin{tabular}{|c|c|c|}
\hline \multirow[t]{2}{*}{ Area } & \multicolumn{2}{|c|}{ No. of children measured } \\
\hline & Pre-intervention & Post-intervention \\
\hline \multicolumn{3}{|l|}{ Llam } \\
\hline Control area & 524 & 339 \\
\hline Intervention area & 654 & 335 \\
\hline \multicolumn{3}{|l|}{ Bardsir } \\
\hline Control area & 521 & 331 \\
\hline Intervention area & 510 & 381 \\
\hline \multicolumn{3}{|l|}{ Borazjan } \\
\hline Control area & 586 & 359 \\
\hline Intervention area & 531 & 433 \\
\hline
\end{tabular}




\section{Intervention}

Based on the findings of the situation analysis, a range of appropriate nutritional and social intervention strategies were designed to combat malnutrition in the areas. The intervention measures included:

- educating mothers about: breastfeeding, complementary feeding, child feeding in diarrhoea and other diseases, balancing and diversifying diet and food groups, preparing safe drinking water, creating a healthy home environment and family planning,

- reinforcing the growth monitoring programme and sensitizing mothers to children's growth cards,

- strengthening literacy programmes for women,

- increasing access to foods through establishment of rural cooperative stores,

- promoting home gardening,

- granting loans for family self-sufficiency programmes such as carpet weaving, confectionary, tailoring, embroidery and poultry breeding,

- establishing programmes for improved employment and income generation.

Different sectors, agricultural, educational and social, participated in this intervention programme, including a literacy movement organization, social welfare organizations and rural cooperatives.

Safe drinking water. Households that obtained their water from wells and rivers were supplied with concentrated chlorine solution by the behvarz for chlorination of water at home.

Sanitary toilets. To expand the number of sanitary toilets the district health centre supplied plumbers to villagers who needed them. Building the toilet structures and septic tanks were done by the villagers themselves.
Waste disposal. All refuse was collected in containers with lids. Removal was done by volunteers from the villages. The behvarz was responsible for educating people and involving them in this activity.

Health education for a healthy environment. Education about the environment was done by the behvarz with support from peripheral workers from all sectors such as agricultural extension workers, teachers and schoolchildren.

Promotion of breastfeeding. Counselling was done by the behvarz in the health house at the time of prenatal and postnatal check-ups, at consultations and during home visits. Breastfeeding was also promoted via the mass media and with the help of others such as teachers and schoolchildren.

Growth monitoring and promotion. The behvarz were actively involved in the counselling of mothers on the nutritional requirements for children based on the outcome of weighing and charting. The mothers also were taught to interpret their children's growth curves.

Complementary feeding. All health houses were equipped with gas cookers and other necessary items for conducting nutrition classes and the behvarz transported the equipment to satellite villages. The behvarz held demonstrations about correct methods of food preparation for mothers with children in the age groups requiring complementary food as well as for other women of the village.

Home gardening. In order to encourage people to consume more vegetables, agriculture extension workers were involved in the distribution of seeds to health houses and schools. Practical training about nutrition and planting vegetables at home were conducted for women and girls through the rural women's unit of the Bureau of Pro-

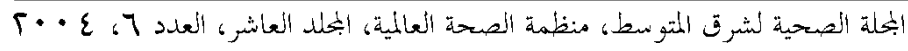


motion of Rural Women and by the agriculture extension workers.

Promoting consumption of dairy products and fruits. The behvarz and peripheral workers from all sectors (welfare organizations, education, and agriculture) were actively involved in nutrition education and awareness about the importance of a balanced and varied diet. Special booklets on nutrition for rural women were designed by nutrition experts and simplified by the literacy movement officers.

Animal husbandry. The department of animal husbandry in the Ministry of Agriculture was involved in encouraging villagers to start rearing livestock and poultry in order to improve the availability of dairy products, meats and eggs and to contribute towards income generation.

\section{Coordination of the intervention}

The organizations involved in the intervention were run at the local government, provincial and district level but the activities had to be coordinated at the national level. The literacy movement is a department in the Ministry of Education that is responsible for educating rural illiterate adult women and men. Social welfare is a governmental organization which covers poor people in rural areas (health insurance, food aid, etc.). The rural cooperatives organization is under the Ministry of Agriculture and is responsible for distributions of food items and managing rural markets. The specification of this education intervention was that all relevant government sectors were actively involved in educating the people in the villages. Training workshops were conducted for them through provincial health centres.

\section{Evaluation}

In the evaluation carried out 3 years after the start of the intervention, anthropomet- ric data collected in the first phase were again gathered through measuring the weight and height of children aged 6-35 months who were selected by a sampling method similar to the first phase. The weight and height of randomly selected children in the control districts were also measured.

\section{Analysis}

The data were analysed using Epi-Info, version 6.0. Differences in the prevalence of underweight, stunting and wasting were assessed in the intervention and control areas comparing the values before (1996) and after (1999) implementation of the intervention.

\section{Results}

\section{Intervention areas}

Figure 1 shows the percentage prevalence of underweight, stunting and wasting in the 3 intervention areas before and after implementation of the intervention. All indicators of malnutrition decreased in all areas after the intervention (except for wasting in Ilam).

A small non-significant decrease in percentage prevalence of underweight (weight-for-age) was seen in Ilam (12\% to $10 \%)$, whereas in Borazjan and Bardsir the prevalence of underweight was halved after the intervention $(23 \%$ to $11 \%$ in Borazjan and $28 \%$ to $14 \%$ in Bardsir) $(P<$ 0.0001).

Figure 1 also shows that nutritional stunting (height-for-age) greatly decreased in all areas $(25 \%$ to $12 \%$ in Ilam, $41 \%$ to $13 \%$ in Borazjan and $31 \%$ to $19 \%$ in Bardsir) $(P<0.0001)$.

The percentage prevalence of wasting (weight-for-height) decreased in Borazjan $(9 \%$ to $4 \%)(P<0.0001)$ (Figure 1$)$. In 


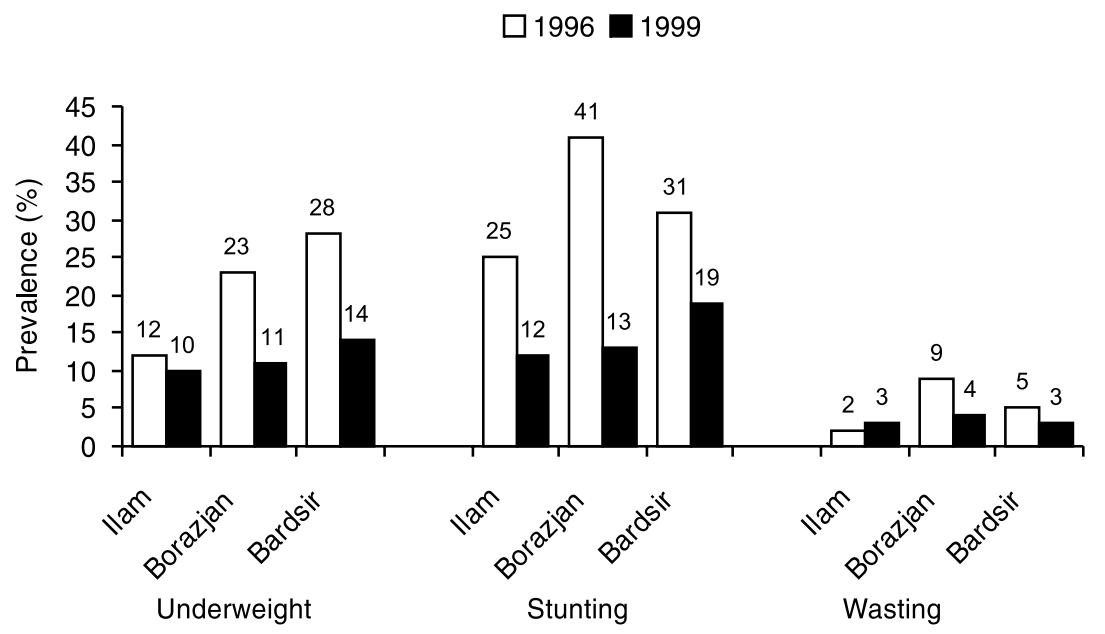

Figure 1 Comparison of prevalence percentage of malnutrition indicators in intervention areas of Ilam, Borazjan and Bardsir in 1996 and 1999 (before and after the intervention)

Bardsir, a small decrease in wasting was seen $(5 \%$ to $3 \%)$, but this was not statistically significant. The prevalence of wasting increased slightly in Ilam (2\% to $3 \%)$, but not significantly so.

\section{Control areas}

Figure 2 shows the percentage prevalence of malnutrition in control areas of the 3 provinces in the same years as the intervention period (1996 and 1999). In 1996, levels of malnutrition were generally lower in control areas than in intervention areas. While some decreases in underweight, stunting and wasting were recorded in 1999 , these were much smaller than in intervention areas.

Underweight decreased in control areas of Borazjan (13\% to $8 \%)(P>0.05)$ and Bardsir $(24 \%$ to $16 \%)(P<0.0001)$, but the prevalence of underweight increased in Ilam over the 3 years ( $9 \%$ to $12 \%$ ).

Similarly, stunting increased in Ilam (13\% to $17 \%)$, and small decreases were seen in Borazjan (16\% to $15 \%)(P>0.05)$ and Bardsir $(37 \%$ to $30 \%)(P<0.03)$.
The prevalence of wasting changed little over the 3 years in all areas (from $2 \%$ to $4 \%$ in Ilam, from 5\% to 4\% in Borazjan and $3 \%$ to $3 \%$ in Bardsir).

\section{Discussion}

Our intervention for reducing children's malnutrition was based on the triple-A approach (Assessment-Analysis-Action) proposed by UNICEF in 1989 [6]. The initial assessment and analysis of the situation determined the key factors affecting the prevalence of malnutrition, while the evaluation phase determined the effectiveness of interventions. Other studies, in different countries such as Thailand, India and the Philippines, present considerable evidence about the usefulness of such interventions. In Thailand, the Family Nutrition Improvement programme used multicultural initiatives, including growth monitoring of children under 5 years old, practical nutrition education, promotion of home gardening, iron and vitamin A supplementation and

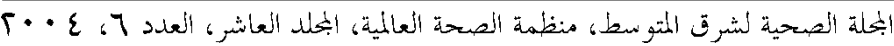




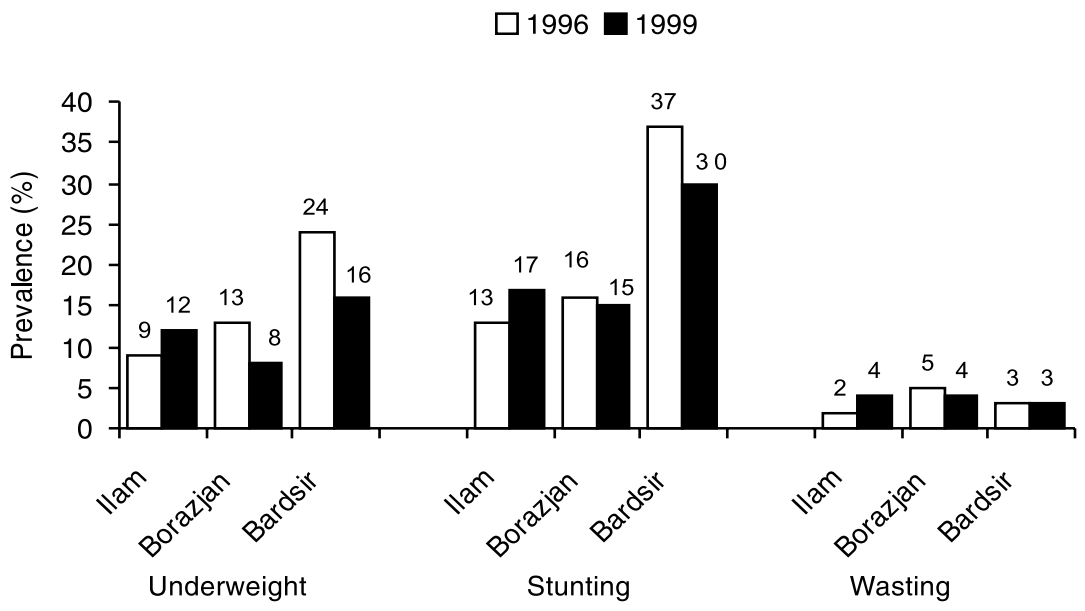

Figure 2 Comparison of prevalence percentage of malnutrition indicators in control areas of Ilam, Borazjan and Bardsir in 1996 and 1999

treatment of diarrhoea with oral dehydration solutions [7]. These were performed with the participation of the community and trained volunteers. Evaluation of this programme showed that it led to positive changes in knowledge and practice of households regarding children's growth. For this project, the government of Thailand assigned all of its resources and facilities to the selected interventions.

In the Integrated Child Development Services project in 1975, India carried out an integrated initiative for children under 5 years and for pregnant and lactating women, through food grants, food supplements and immunization and nutrition education by health and social workers. Evaluation of the programme showed a decrease of severe malnutrition in centres covered by the scheme. One of the essential factors in the success of that programme was the training of workers and continuous supervision at the local level, which led to promotion of their skills [6].

In the Philippines, the Philippines Nutrition Programmes has since 1974 carried out thorough growth monitoring of children less than 5 years old using rural volunteers. The volunteers were involved in weighing children, nutrition education, family planning services, immunization and other health services. This programme was supported by government and succeeded in its aims, despite the political instabilities in the country [7].

Similar to our study, South Africa performed the Integrated Nutrition Programme in its primary health care system, as a pilot in 4 provinces in 1997. The main activities of that programme, which was achieved by intersectoral participation, were training of teachers, farmers and other volunteers interested in food self-sufficiency, promotion of the health of women and children, promotion of exclusive breastfeeding of children under 6 months and continuing breast feeding for 2 years and establishing "nutrition rehabilitation centres". After evaluation of the programme at the end of 1998, it was extended nationwide $[8]$. 
In the present study, strengthening the existing growth monitoring programme and sensitization of mothers to children's growth cards were considered key strategies for promoting the growth of children. In the Family Nutrition Improvement Programme in Indonesia, growth monitoring of children proved to be effective as an educational means for timely recognition and control of children's growth disorders [9].

One of the specifications of our study was the reliance on nutrition education, without resorting to food grants. Although food grants programmes for children in Senegal, Morocco, Sri Lanka, Tanzania and India have had good effects, programmes based on nutrition education alone have also been successful. As an example, a community-based intervention through nutrition education performed in the Dominican Republic showed that the prevalence of moderate and severe malnutrition in children aged 2-3 years decreased to one-third of its initial figure 3 years after the intervention [10]. The beneficial effects of nutrition education on the nutrition status of low-income pregnant Mexican women is another example of a successful intervention [11].

This 3-year intervention for decreasing malnutrition in rural areas of the Islamic
Republic of Iran with the cooperation of different community and NGO sectors resulted in a significant decrease in all malnutrition measures among under-3-year-olds. The success of our programme, as in interventions in other countries, may be attributed to the intersectoral cooperation and participation of all development sectors to tackle the multidimensional causes of malnutrition.

\section{Acknowledgements}

This study was performed with the kind cooperation of UNICEF and the governorgenerals and heads of the medical universities of Ilam, Kerman and Bushehr provinces. We appreciate the effort and cooperation of the agriculture ministry, the education ministry, the literacy movement organization, the social welfare organizations, the rural cooperative organizations, health centres of districts and provinces, Institute of Nutrition and Food Science Research, and School of Public Health (Tehran University of Medical Sciences). This survey could not have been fulfilled without the valuable support of Dr Hossein Malekafzali, ex-consultant to the Minister of Health and Medical Education.

\section{References}

1. United Nations Children's Fund. The state of the world's children. New York, Oxford University Press, 1995:7-21.

2. Ministry of Health and Medical Education/UNICEF. The nutrition status of children, 1st ed. Tehran, Senobar, 1998.

3. Savage-King F, Burgess A. Nutrition for developing countries, 2nd ed. Oxford, Oxford University Press, 1993:209-20.

4. Kielmann AA, Taylor CE, Parker RL. The Narangwal nutrition study: a summary review. American journal of clinical nutrition, 1978, 31: 2040-57.

5. Physical status: the use and interpretation of anthropometry. Report of a WHO Expert Committee. Geneva, World Health Organization, 1995 (WHO Technical Report Series, No. 854).

6. Gurney JM. A situation analysis and agenda for the turn of the century for countries of the south-east region of WHO. Part I: program file (nutrition). Pa-

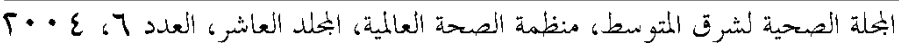


per discussed in the FAO/WHO Asia and Pacific Regional Meeting, Bangkok, 1992:27-31.

7. Winichagoon $\mathrm{P}$ et al., eds. Integrating food and nutrition into development: Thailand's experiences and future visions. Bangkok, Institute of Nutrition, Mahidol University at Salaya, and UNICEF East Asia and Pacific Regional Office, 1992:7-9,72-3.

8. Dladla N. Integrated nutrition program. South Africa, UNICEF, 1999:2-7.

9. Beaton GB, Ghassemi H. Supplementary feeding programs for young children in developing countries. American journal of clinical nutrition, 1982, 35(4 suppl.):863-916.

10. Ghassemi H. Supplementary feeding programs in developing countries: lessons of the eighties. Part II: discussion and references. Asia Pacific journal of clinical nutrition, 1992, 1:195-206.

11. Hunt IF et al. Effect of nutrition education on the nutrition status of low-income pregnant women of Mexican descent. American journal of clinical nutrition, 1996, 29:675-84.

\section{Global Strategy for Infant and Young Children Feeding}

WHO and UMICEF jointly developed this global strategy to focus world attention on the impact that feeding practices have on the nutritional status, growth and development, health, and thus the very survival of infants and young children. The strategy is the result of a comprehensive two-year participatory process. It is based on the evidence of nutrition's significance in the early months and years of life, and of the crucial role that appropriate feeding practices play in achieving optimal health outcomes. The strategy is intended as a guide for action; it identifies interventions with a proven positive impact, it emphasizes providing mothers and families the support they need to carry out their crucial roles, and it explicitly defines the obligations and responsibilities in this regard of governments, international organizations and other concerned parties. This document is available on line at: http://www.who.int/child-adolescent-health/New_Publications/NUTRITIOM/gs_iycf.pdf 